Ciência Florestal, Santa Maria, v. 22, n. 1, p. 47-58, jan.-mar., 2012

ISSN 0103-9954

\title{
FENOLOGIA DA ANDIROBA (Carapa guianensis, Aubl., MELIACEAE) NO SUL DO ESTADO DE RORAIMA
}

\author{
PHENOLOGY OF ANDIROBA(Carapa guianensis, Aubl., MELIACEAE) IN \\ SOUTH OF RORAIMA STATE
}

\author{
Maria Rutinéia Nobre Pereira ${ }^{1}$ Helio Tonini ${ }^{2}$
}

\begin{abstract}
RESUMO
O presente estudo foi realizado com o objetivo de estudar o padrão fenológico da espécie arbórea Carapa guianensis, Aubl., em floresta natural localizada no sul do estado de Roraima, procurando relacionar a frequência de ocorrência das fenofases às condições pluviométricas do período. Para o levantamento fenológico foram selecionados 20 indivíduos adultos localizados em uma parcela permanente de 9 ha. As observações fenológicas ocorreram quinzenalmente de fevereiro de 2006 a fevereiro de 2009, registrando-se a presença ou ausência dos eventos de floração, frutificação e mudança foliar para cada árvore. Para analisar a influência da precipitação na fenologia da espécie foi utilizado o coeficiente de correlação de Spearman e, para estimar a sincronia dos eventos fenológico utilizou-se o índice de sincronia da população (Z). A floração da andiroba mostrou-se subanual, sincrônica e correlacionada negativamente com precipitação no período do evento fenológico. Foram observados dois ciclos de floração, sendo um longo com inicio em outubro, estendendo-se para o ano seguinte, por um período médio de 9 meses, e um curto com duração de dois meses (julho a agosto). A frutificação é anual, longa e sincrônica, e correlacionou-se positivamente com a precipitação. A época ideal para a coleta dos frutos maduros no local estudado é durante o período chuvoso, que compreende abril a julho. A emissão de folhas ocorreu de forma contínua e não se correlacionou com a precipitação. Observou-se uma maior proporção de indivíduos perdendo folhas, entre os meses de agosto a novembro, que caracterizam um período de transição entre a época seca e chuvosa, com sensível redução de precipitação.
\end{abstract}

Palavras-chave: Amazônia; floração; frutificação; emissão e queda das folhas.

\begin{abstract}
This work was carried out in order to study the phenological pattern of Andiroba in natural forest located in the south of Roraima state, seeking to relate the frequency of phenol-phases occurrence with the rain rate in this period. For the phenological survey 20 adult trees were selected in a permanent sample plot of 9ha. The visits to phenological observations occurred fortnightly from February 2006 to December 2008, recording the presence or absence of flowering, fruiting and leaf change events for each tree. The Spearman correlation was used for analyzing the influence of rainfall on phenology and, the index of synchrony of population $(Z)$ was used for estimating the synchrony of phenological events. The flowering of Andiroba showed to be sub-annual, synchronous and was negatively correlated with the rainfall during the phenological event. Two cycles of flowering were observed: a long one from October until next year, which lasts about nine months, and a short one lasting two months, from July to August. The fruiting is annual, long and synchronous and it was positively correlated with rainfall. The ideal time for collecting ripe fruits at the study site is during the rainy time, that is, from April to July. The leaf flushing was continuous and did not correlate with the rainfall. It was noticed a higher proportion of trees falling leaves between August and November, which characterizes a period of transition between the dry and the rainy period with sensitive reduction of rainfalls.
\end{abstract}

Keywords: Amazon; flowering; fruiting; leaf flush and leaf fall.

1. Engenheira Agrônoma, Mestre em Agronomia, Av. Brigadeiro Eduardo Gomes, 4358, Bairro Aeroporto, CEP 69304-650, Boa Vista (RR). ruti.ibama@gmail.com

2. Engenheiro Florestal, Pesquisador do CPAF Embrapa Roraima, BR 174, Km 08, Distrito Industrial, CEP 69301-970, Boa Vista (RR). helio@cpafrr.embrapa.br

Recebido para publicação em 11/11/2009 e aceito em 21/03/2011 


\section{INTRODUÇÃO}

A região amazônica compreende a maior extensão de ecossistemas tropicais nativos, exercendo influência direta nos ciclos biogeoquímicos globais, principalmente no ciclo do carbono (BERNOUX et al., 2001), e nos últimos 30 anos perdeu cerca de $14 \%$ de sua cobertura florestal original (LENTINI et al., 2005).

A Amazônia representa uma das últimas áreas de floresta tropical do planeta, onde ainda existe possibilidade concreta de tornar compatível a conservação dos recursos naturais com o desenvolvimento socioeconômico da região. Tal possibilidade baseia-se no fato de que grande parte da floresta ainda se mantém intacta (GASCON e MOUTINHO, 1998). Dentro desta perspectiva, projetos que viabilizem a inserção socioeconômica de populações tradicionais, mediante a utilização sustentável dos recursos naturais, são essenciais para o desenvolvimento ordenado da Amazônia. Contudo, nenhuma ação de exploração dos recursos naturais pode ser sustentável ao longo do tempo se não tiver como base pesquisas científicas a respeito da ecologia das espécies com potencial econômico. A sustentabilidade ecológica dos planos de manejo florestal visando o uso múltiplo das florestas tropicais deve incluir critérios e indicadores que garantam a manutenção da variabilidade genética das espécies e processos correlacionados. No entanto, conhecimentos básicos sobre os parâmetros que regulam os processos reprodutivos de espécies arbóreas tropicais ainda são insuficientes (KANASHIRO et al., 2002).

A espécie Carapa guianensis, Aubl pertence à família Meliaceae, sendo conhecida comumente como andiroba e possui ampla distribuição no Neotrópico e Paleotrópico (LEITE, 1997). Ocorre no sul da América Central, Colômbia, Venezuela, Suriname, Guiana Francesa, Peru, Paraguai e Brasil. No Brasil, ocorre na bacia Amazônica, principalmente nas várzeas próximas ao leito de rios e faixas alagáveis ao longo dos cursos d'água, sendo encontrada também em terra firme.

A andiroba trata-se de uma espécie alógama (Maués, 2006), com inflorescência composta por uma panícula de $20-90 \mathrm{~cm}$ de comprimento, sustentada por brácteas axilar ou subterminal (FERRAZ et al., 2002). De acordo com Rizzini e Mors (1976), as flores são pequenas com pétalas de, no máximo, $8 \mathrm{~mm}$ de comprimento, unissexual, sésseis ou subsésseis, glabras, subglobosas de cor branca ou creme, levemente perfumada.

Os frutos são do tipo cápsula globosa e subglobosa com 4 a 6 valvas indeiscentes (PENNINGTON et al., 1981), que se separam com o impacto da queda do fruto (LOUREIRO et al., 1979). As sementes são flutuantes e podem ser dispersas através dos cursos de água, podendo germinar enquanto flutuam (SCARANO et al., 2003).

$O$ óleo da andiroba tem demanda internacional e é utilizado para a iluminação, na confecção de sabão e velas, na indústria de cosméticos e na medicina popular, apresentando funções cicatrizantes, anti-inflamatórias, antihelmínticas e inseticida. O chá da casca e das folhas é utilizado como remédio para combater infecções e no tratamento de doenças da pele (GONÇALVES, 2001, FERRAZ et al., 2002, SHANLEY, 2005, QUEIROZ, 2007). O óleo de andiroba é composto de oleína e palmitina e menores proporções de glicerina. As amêndoas contêm: lipídios, fibras, minerais e ácidos graxos do óleo. Revilla (2000) e Sampaio (2000) relataram a seguinte composição: umidade $40,2 \%$, proteína $6,2 \%$, gordura $33,9 \%$, fibra bruta $12,0 \%$, cinzas $1,8 \%$ e carboidratos $6,1 \%$.

A fenologia estuda a ocorrência de eventos biológicos repetitivos, como os reprodutivos, e os efeitos responsáveis pelo desencadeamento destes em relação a fatores bióticos e abióticos, dentro de uma ou várias espécies de plantas (LEIGHT et al., 1974). A importância de se conhecer a fenologia de uma determinada espécie está na necessidade de estudar a sua biologia reprodutiva para que se possam definir estratégias sustentáveis de uso. Através da fenologia é possível conhecer como é organizada a distribuição temporal dos recursos (flores e frutos), entender a dinâmica de reprodução e regeneração das plantas, e a relação entre as plantas e os animais (CALVIN e PINA-RODRIGUES, 2005).

Este trabalho foi realizado com o objetivo de estudar o padrão fenológico da andiroba em ambiente natural e relacionar a frequência de ocorrência das fenofases às condições pluviométricas do período.

\section{MATERIAL E MÉTODOS}

\section{Características do local de estudo e amostragem}

Os dados foram coletados em uma floresta com ocorrência natural de andiroba, no sul do estado de Roraima, no município de São João da Baliza (Figura 1), localizado nas coordenadas $00^{\circ} 57^{\prime} 02^{\prime \prime}$ de latitude Norte e 59 54'41" de longitude Oeste, distante $313 \mathrm{Km}$ da capital Boa Vista. 

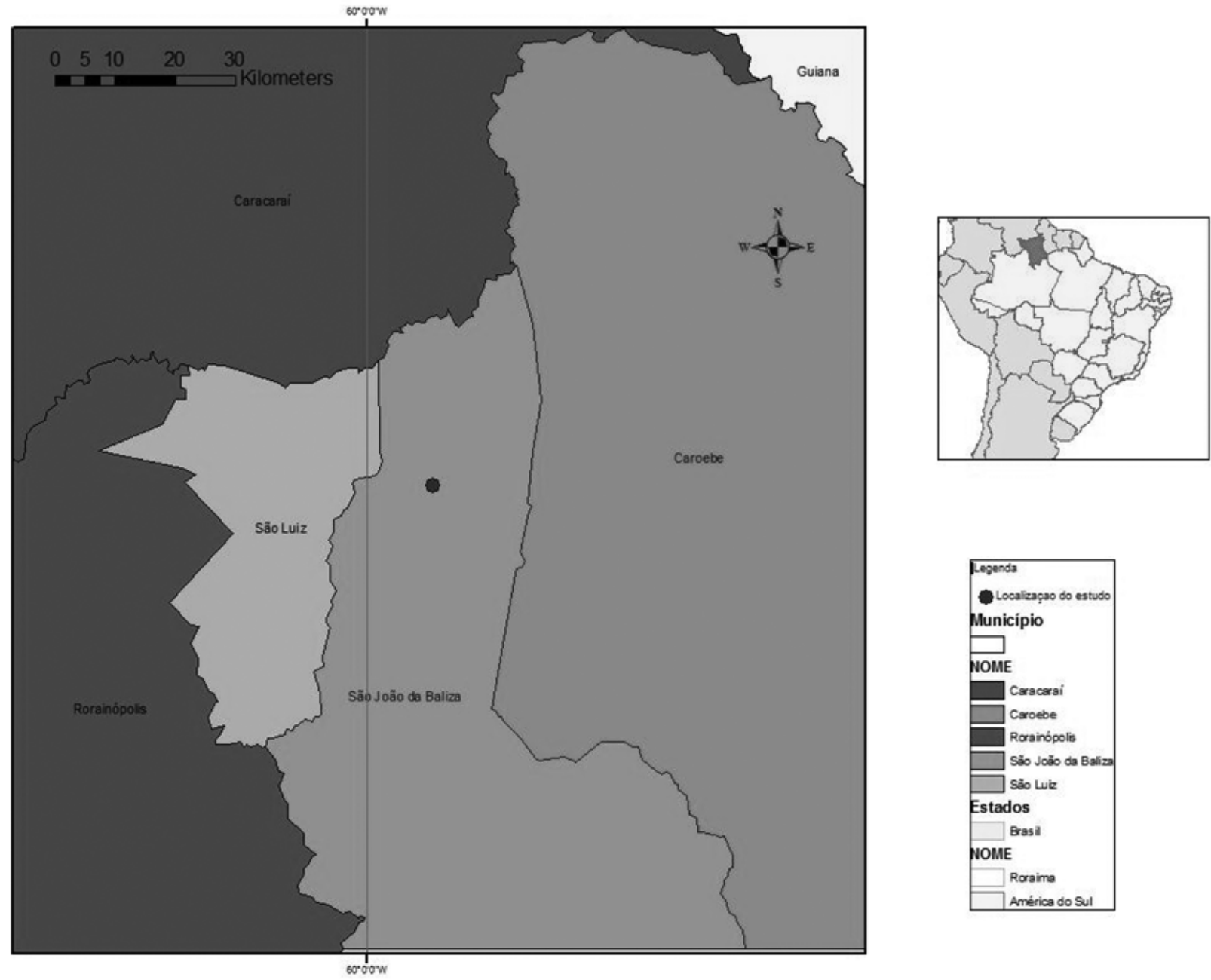

FIGURA 1: Localização da área de estudo no estado de Roraima.

FIGURE 1: Study area location in Roraima state.

A área em estudo localiza-se na reserva legal de um lote com 100 ha de área total. As árvores estavam localizadas em uma parcela permanente de 9 ha, instalada pela Embrapa Roraima, para a realização de estudos de ecologia e manejo de espécies de uso não madeireiro como a castanheirado-brasil (Bertholetia excelsa) e a andiroba (Carapa guianensis). Aárea apresenta relevo plano a ondulado com a vegetação predominante considerada como floresta ombrófila densa (BRASIL, 1975) em área de terra firme.

O clima na região é classificado como Ami (tropical chuvoso com pequeno período de seca), com precipitação média anual entre 1.700 e $2.000 \mathrm{~mm}$. O período chuvoso ocorre com maior frequência de abril a agosto, com totais mensais superiores a $100 \mathrm{~mm}$. A partir de setembro ocorre uma sensível redução, com período caracteristicamente seco ocorrendo mais frequentemente de novembro a março. A temperatura média anual é de $27^{\circ} \mathrm{C}$ (AMBITEC, 1994).

Os dados fenológicos foram obtidos em 20 indivíduos adultos, com copas bem formadas, dominantes (de posição superior no dossel) e livres de infestações por cipós. A diferenciação entre estratificar a população em jovens (DAP $\leq 30 \mathrm{~cm})$ e adultos $(\mathrm{DAP}>30 \mathrm{~cm})$ jovens e adultos foi realizada com base no estudo de Tonini et al. (2009) que, para a mesma população, definiram o DAP de 30 $\mathrm{cm}$ como limítrofe para a produção comercial de sementes.

\section{Coleta e análise de dados}

As visitas para as observações fenológicas ocorreram quinzenalmente, de fevereiro de 2006 a fevereiro de 2009, e consistiram na coleta de dados sobre a presença ou ausência dos eventos de floração, frutificação e mudança foliar para cada árvore. Os dados de precipitação foram obtidos com 
a instalação de um pluviômetro no local. Para a visualização das fenofases utilizou-se um binóculo.

Os critérios utilizados para a definição dos tipos de floração e frutificação foram: a) frequência (número de ciclos por unidade de tempo), b) duração (tempo passado em cada ciclo fenológico), c) época (dia, mês ou estação do ano em que o evento ocorre) e d) sincronia (ocorrência simultânea de um evento fenológico). As estratégias de floração e frutificação adotadas neste trabalho seguiram as definições de Morellato (1991) e Newstron e Frankie (1994).

Para a análise dos dados verificou-se o número de árvores em cada evento fenológico, e em seguida calculou-se a porcentagem de indivíduos em cada fase fenológica.

Uma vez que, em regiões tropicais, as estações são marcadas por diferenças de precipitação, e sendo este considerado o principal fator que influencia os padrões fenológicos das espécies em florestas tropicais com estações bem definidas e sazonalidade evidente na precipitação anual (AUGSPURGER, 1981, MORELLATO, 1991) foi analisada a relação entre a precipitação e a fenologia da espécie Carapa guianensis, através do coeficiente de correlação de Spearman (r).

A frequência de ocorrência das fenofases foi correlacionada com a precipitação no mesmo mês, no mês anterior e dois meses anteriores ao evento fenológico.

Para estimar a sincronia dos eventos fenológicos utilizou-se o índice de sincronia da população (Z), conforme Augspurger (1983), que é expresso por:

$$
Z=\frac{1}{n} \sum_{i=1}^{n} x_{i}
$$

Onde: $\mathrm{n}=$ número de indivíduos na população; $\mathrm{x}_{\mathrm{i}}=$ sincronia do indivíduo i com seus coespecíficos.

A sincronia de um determinado indivíduo com seus coespecíficos ou o índice de sincronia individual $\left(\mathrm{x}_{\mathrm{i}}\right)$ é definida por:

$$
X_{i}=\left(\frac{1}{n-1}\right) x\left(\frac{1}{f_{i}}\right) x \sum_{j=1}^{n} e_{j=1}
$$

Onde: $e_{j}=$ número de meses que os indivíduos $\mathrm{i}$ e $\mathrm{j}$ estão na mesma fenofase; $\mathrm{f}_{\mathrm{i}}=$ número de meses em que o indivíduo i esta na fenofase; $\mathrm{n}=$ número de indivíduos na população.
Quando $X=1$ ocorre a sincronia perfeita; para $\mathrm{X}=0$, não existe sincronia no evento fenológico.

\section{RESULTADOS E DISCUSSÃO}

\section{Floração}

A floração prolongou-se praticamente ao longo dos três anos de coleta de dados na população analisada, sendo, no entanto, mais intensa no período de menor precipitação pluviométrica, com máxima atividade entre dezembro e a fevereiro. A floração pode ser considerada subanual segundo a classificação de Newstron e Frankie. (1994), longa e sincrônica $(Z=0,88)$.

Foram observados dois ciclos de floração, sendo um longo com início em outubro, estendendose para o ano seguinte por um período médio de 9 meses e um curto com duração de dois meses (julho a agosto). De acordo com a classificação de Gentry (1974), Carapa guianensis segue o padrão steadystate, uma vez que são encontrados indivíduos com flores praticamente ao longo do ano todo.

A longa floração não corrobora com Boufleuer (2004), que em estudo realizado no noroeste do estado do Acre, verificou que aproximadamente $50 \%$ dos indivíduos floresceram anualmente entre o período de junho a setembro, apresentando florescimento curto (3 meses) e evidenciando sincronia regular dentro da população. Raposo et al. (2003), ao estudarem a floração de andiroba na região de Rio Branco-AC, verificaram que a mesma ocorreu no período de outubro a dezembro, o que sugere uma assincronia entre estas duas populações no estado do Acre.

A sincronia de floração tem importante papel em espécies dióicas, que está relacionado à seleção sexual exercida pelas fêmeas quanto à qualidade e quantidade do pólen que chega até as mesmas e, consequentemente, às taxas de endogamia na população. Alternativamente, a sincronia reprodutiva poderia atuar de maneira a aumentar a atratividade aos polinizadores e diminuir perdas ocasionadas por herbivoria (AUGSPURGER 1983; HALL et al., 1996).

O segundo período de floração não resultou na formação de frutos novos. Embora as espécies tropicais floresçam anualmente, alguns autores identificaram que algumas espécies tropicais não produzem frutos frequentemente, fato relatado para família Lecythidaceae (LIMA JUNIOR, 1992) e Sapotaceae (ALENCAR, 1994) na Reserva Ducke, no Amazonas. Davis (1976) apud Alencar 
(1990) considera que tais ocorrências estejam correlacionadas com a precipitação.

A floração principal se iniciou no mês de outubro, estendendo-se até o final do mês de julho do ano seguinte, em 2007 e em maio de 2008, por um período médio de 9 meses (Figura 2).

A floração ocorreu predominantemente no período de menor precipitação pluviométrica, concordando com a maioria dos estudos disponíveis sobre a espécie. Maués (2006) em estudos na Floresta Nacional do Tapajós-PA e Mellinger (2006) na Reserva de Desenvolvimento Sustentável Amanã-AM, também verificaram que a floração da andiroba prolongou-se praticamente pelo ano todo na população, sendo discretamente mais intensa no período de menor precipitação pluviométrica. No entanto Plowden (2004), em estudo na reserva indígena Tembé, próxima ao rio Gurupi, município de Paragominas - Pará, identificou um padrão fenológico inverso, com pico de floração no meio da estação chuvosa, e a maioria dos frutos começando a cair no início da estação seca.

Outros estudos corroboram com nossos resultados, como os de Carvalho (1980) e Alencar (1988), realizados na Amazônia brasileira envolvendo comunidades florestais que revelaram que no período de menor precipitação pluviométrica (estiagem) a floração se mostrou presente para a maioria das espécies observadas.

$\mathrm{Na}$ Reserva Ducke-AM, Alencar et al. (1979) relataram que os períodos de floração e frutificação ocorreram, para maioria das espécies estudadas na dependência da distribuição das chuvas, com dominância da floração na estação seca e maior incidência de frutos maduros no período chuvoso. Já Pinto et al. (2005) em estudos na Reserva DuckeAM verificaram que para espécie Simarouba amara o valor máximo da fase "plena floração" ocorreu no mês de dezembro, no início da estação chuvosa.

No presente estudo verificou-se que em 2006, a floração apresentou maior sincronia nos meses de fevereiro e dezembro com 95 e $90 \%$ dos indivíduos florescendo. No ano de 2007 verificou-se uma maior proporção de indivíduos na fenofase nos meses de janeiro e dezembro, quando $100 \%$ e $86,1 \%$ dos indivíduos observados apresentaram flores respectivamente. Em 2008, os meses de novembro e dezembro apresentaram o maior percentual de indivíduos na fenofase com 94,4 e $88,9 \%$ dos indivíduos florescendo (Figura 2).

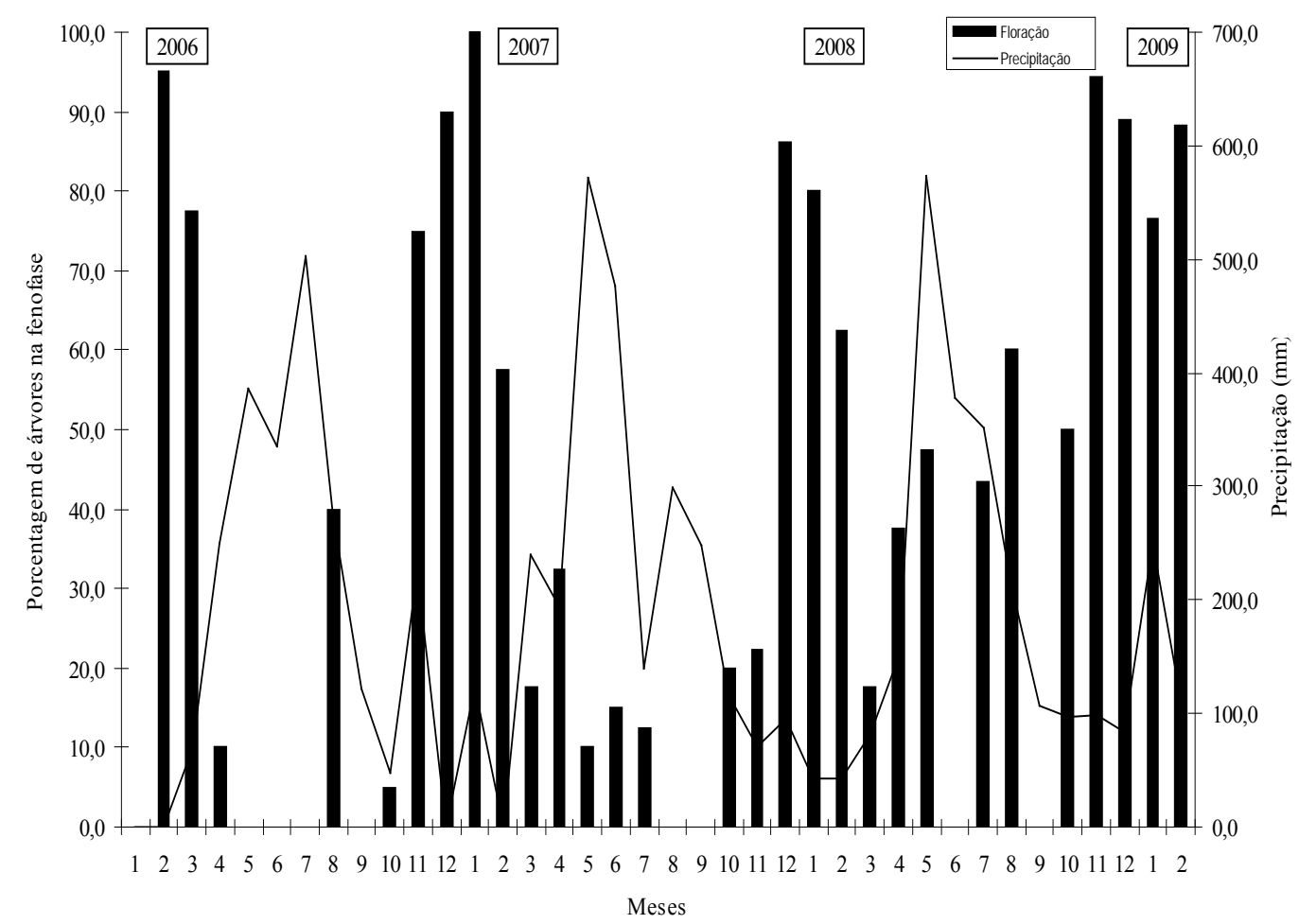

FIGURA 2: Porcentagem de indivíduos de Carapa guianensis Aubl. em floração registrada quinzenalmente no período de fevereiro de 2006 a fevereiro de 2009, no município de São João da Baliza, Roraima, Brasil.

FIGURE 2: Percentage of flowering for Carapa guianensis Aubl., recorded fortnightly from February 2006 to February 2009 the city of São João da Baliza, Roraima state, Brazil. 
A floração correlacionou-se negativamente com a precipitação no período da ocorrência do evento $(r=-0,467, p=0,01)$ de forma que o número de plantas florescendo aumentou com a diminuição da precipitação. Borchet (1983) comenta que, quando se analisa o comportamento da floração em espécies tropicais, é importante considerar que estes padrões devem ser explicados como resultado do contexto geral de desenvolvimento da árvore determinado por fatores climáticos, edáficos e bióticos, o que, de certa forma, explica o baixo valor de $\mathrm{r}$ observado. Fatores abióticos como a precipitação, podem interferir sobre a floração diretamente por afetarem a habilidade de uma planta em produzir flores ou, indiretamente, por afetarem os polinizadores (RATHCKE e LACEY, 1985). Segundo Van Schaik et al. (1993) a abundância de polinizadores pode variar sazonalmente e o número de polinizadores é maior durante a estação seca, o que favorece a estratégia de florescer no período seco. No entanto, Tutim e Fernandes (1993) afirmaram que é necessário ter cautela ao se relacionar as fenofases reprodutivas com a estação chuvosa em florestas tropicais. Os autores observaram que as temperaturas mínimas ocorridas na estação seca anterior às primeiras chuvas foi o principal fator ambiental relacionado à frutificação de algumas espécies em florestas úmidas no Gabão.

\section{Frutificação e dispersão}

A frutificação (Figura 3) pode ser considerada anual, longa e sincrônica $(Z=0,93)$. Janzen (1976) relata que a frequência irregular de frutificação é considerada uma estratégia adaptativa para reduzir a predação de sementes através da saciação dos predadores. Períodos de grande produção de sementes seguidos de períodos de escassa produção regulam as populações de predadores (SILVERTOWN, 1980).

Segundo Leight (1999) árvores com sementes grandes, atrativas a roedores como as cutias, devem ser sincrônicas na frutificação, pois, quando os frutos são abundantes as cutias enterram mais sementes e a probabilidade de que estas sementes não sejam novamente encontradas e germinem é maior. De acordo com o autor, no Panamá Central, a maioria das sementes grandes escapa do ataque de insetos somente se é enterrada por roedores.

Em 2006 a frutificação iniciou em março com a maior proporção de indivíduos apresentando frutos novos no mês de abril (45\%). Em 2007 e
2008 a frutificação iniciou em janeiro com pico nos meses de fevereiro em 2007 (92,5\% dos indivíduos observados com frutos novos) e março em 2008 $(87,5 \%$ dos indivíduos observados com frutos novos).

O tempo médio de amadurecimento dos frutos por árvore foi de 3 meses, sendo bastante inferior ao descrito pela EMBRAPA (2004) de quase um ano.

O período de frutificação da andiroba na Amazônia varia com a região. No estado do Acre, pode ocorrer entre setembro e março (BOUFLEUER, 2004), e na Amazônia Oriental de janeiro a julho (SHANLEY, 2005). O período de desenvolvimento dos frutos na Floresta Nacional dos Tapajós (PA) foi registrado entre os meses de outubro a julho (MAUÉS, 2006). Já Pena (2007) identificou o período de frutificação na época chuvosa com pico no mês de fevereiro no sudeste do Pará.

A dispersão (queda dos frutos) ocorreu, predominantemente, no período de maior precipitação (abril a agosto) corroborando com os resultados de Mellinger (2006) e Pena (2007) que também identificaram o período de dispersão de frutos na época chuvosa na Reserva de Desenvolvimento Sustentável Amanã no Amazonas, e no sudeste do Pará, respectivamente. Com a queda dos frutos e dispersão das sementes ocorrendo no período chuvoso, pode-se supor que a germinação das sementes e o estabelecimento das plântulas sejam beneficiados pela água e nutrientes liberados pela decomposição da matéria orgânica, acumulada durante o período seco (MORELLATO et al., 1989). Adispersão da andiroba é principalmente barocórica, ou seja, os frutos maduros caem pela força da gravidade, sendo dispersos secundariamente por mamíferos de médio a grande porte. Em ambientes com cursos d'água próximos às árvores, ocorre também a dispersão hidrocórica (MAUES, 2006).

A dispersão pode ser considerada anual, curta e sincrônica $(Z=0,80)$, tendo início em abril estendendo-se até agosto, com duração média de 5 meses.

Em 2006, a dispersão dos frutos iniciou no mês de abril estendendo-se até o final de agosto, com pico no mês de maio $(87,5 \%$ dos indivíduos dispersando os frutos). Em 2007, a dispersão iniciou-se em março estendendo-se até o final de agosto, com pico nos meses de abril, maio e junho com $82,5 \%, 90 \%$ e $77,5 \%$. Em 2008, a dispersão iniciou-se em abril, estendendo-se, como nos anos anteriores, até o final de agosto, com pico nos meses 

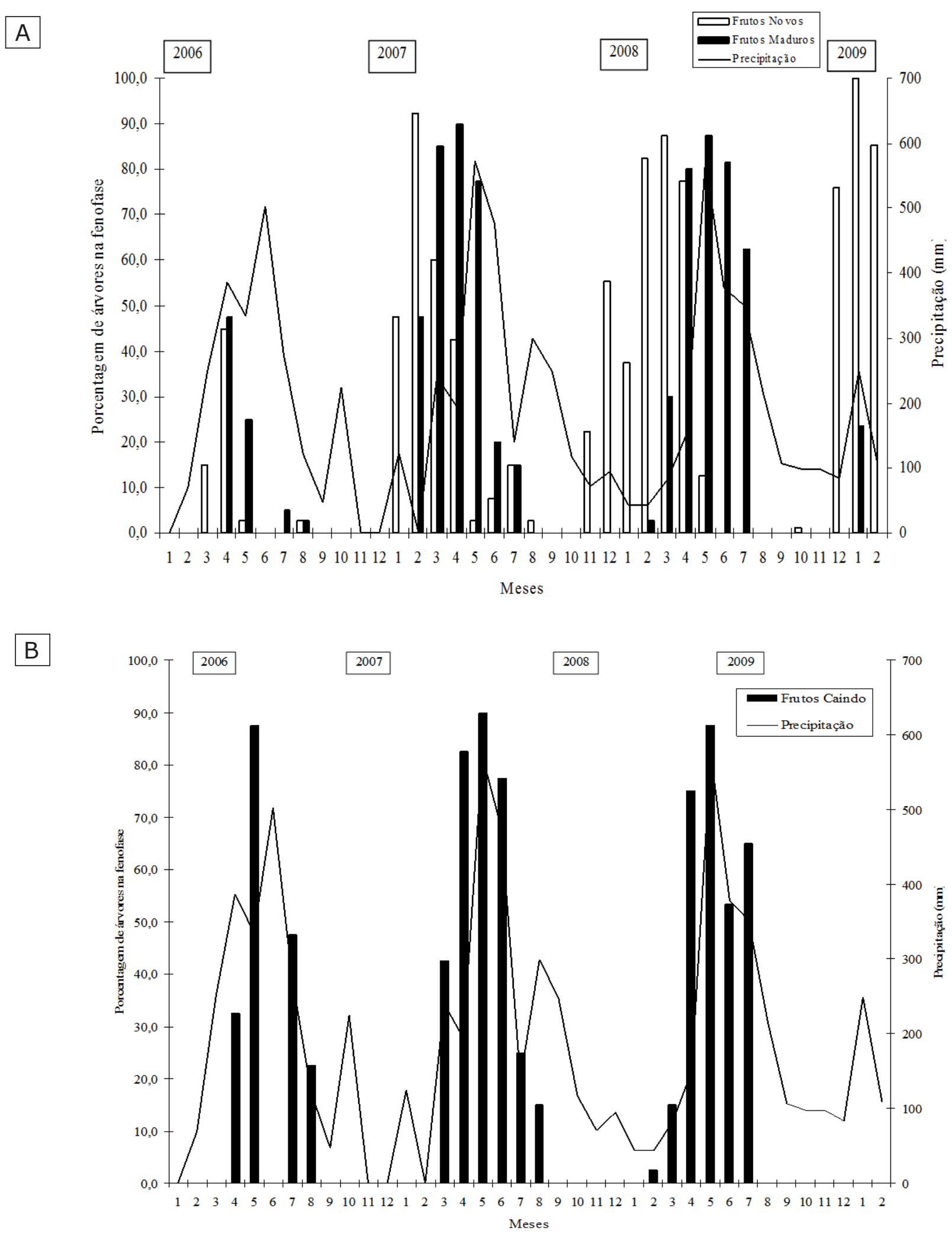

FIGURA 3: Porcentagem de indivíduos de andiroba em frutificação registrada quinzenalmente, no período de fevereiro de 2006 a fevereiro de 2009: A.) Frutos novos e maduros e B.) Frutos caindo, no município de São João da Baliza, Roraima, Brasil.

FIGURE 3: Percentage of fruiting for Andiroba trees, recorded fortnightly from February 2006 to February 2009; A.) New and Ripe Fruits. B) Falling fruits, city of São João da Baliza, Roraima state, Brazil. 
de maio e junho, com $75 \%$ e $87,5 \%$ dos indivíduos dispersando os frutos, respectivamente.

A dispersão dos frutos correlacionou-se mais fortemente com a precipitação no período $(\mathrm{r}=0,763, \mathrm{p}=0,01)$ de forma que, quanto maior a precipitação, maior o número de árvores que dispersam os seus frutos. Ferraz et al., (1999) também observaram que a frutificação de Croton floribundus, Cedrela fissilis e Cordia ecalyculata correlacionou-se positivamente com a precipitação, no período de produção dos frutos. Para Foster (1992) a dispersão das espécies é controlada pela época que apresenta as condições mais favoráveis para a germinação das sementes. A produção e a queda dos frutos na estaçãoúmida seriam vantajosas, pois aumentam a possibilidade de germinação das sementes e o estabelecimento das plântulas. Araújo (1979) e Alencar et al. (1979) também verificaram na Reserva Ducke, para mais de 50 espécies, que a maioria apresentou frutos maduros e frutos caindo na estação chuvosa.

\section{Emissão e queda de folhas}

A emissão e queda foliar não apresentaram sazonalidade distinta e ocorreram de forma sincrônica $(Z=1,0)$, contínua e simultânea na população. Foi observada grande proporção de indivíduos emitindo folhas novas e perdendo folhas velhas ao mesmo tempo durante grande parte do ano, o que concorda com as observações fenológicas realizadas por Boufleuer (2004) no Acre, e Maués (2006) no Pará.

O sincronismo da emissão foliar tem sido sugerido como uma estratégia para evitar a emissão de folhas novas durante estações desfavoráveis (VAN SCHAIK et al. 1993). As folhas, quando produzidas simultaneamente, devem sofrer menos danos do que folhas produzidas fora do pico de brotamento, já que quando há um aumento na disponibilidade de alimento os herbívoros são saciados mais facilmente (JANZEN, 1976).

Em 2006, a emissão de folhas iniciou em fevereiro e estendeu-se até dezembro, com duração de 9 meses, uma vez que não foram observados indivíduos emitindo folhas novas em junho. O pico da emissão de folhas ocorreu no mês de maio, com $100 \%$ dos indivíduos observados apresentando folhas novas. A queda das folhas iniciou em abril e estendeu-se até novembro, com duração de 6 meses, não ocorrendo nos meses de junho e julho, e pico nos meses de agosto e setembro com $100 \%$ e $95 \%$ dos indivíduos perdendo folhas.
Em 2007, a emissão de folhas iniciou em abril estendendo-se até dezembro, com duração de 9 meses e pico entre os meses de junho, novembro e dezembro com $100 \%$ dos indivíduos com folhas novas. A queda das folhas iniciou em junho e estendeu-se até dezembro, com duração de 7 meses e pico nos meses de novembro e dezembro, período com $100 \%$ e $94,4 \%$ dos indivíduos, respectivamente, perdendo folhas.

Em 2008, a emissão de folhas iniciou em janeiro estendendo-se até dezembro, com duração de 12 meses. O pico ocorreu no mês de novembro, com 94,4\% dos indivíduos apresentando folhas novas. A queda das folhas iniciou em janeiro também se estendendo até dezembro, com duração de 12 meses, o pico da queda de folhas ocorreu nos meses de agosto e setembro com $90 \%$ dos indivíduos perdendo folhas (Figura 4).

Durante os três anos observou-se uma maior proporção de indivíduos perdendo folhas entre os meses de agosto a novembro que caracterizam um período de transição entre a época mais chuvosa e a mais seca, com sensível redução de precipitação.

Boufleuer (2004) observou a emissão de folhas novas e a queda de folhas velhas em $100 \%$ dos indivíduos de andiroba observados. Assim, Carapa guianensis pode ser considerada perenifólia, apresentando folhas ao longo de todo o ano. A oferta ou escassez de água, aparentemente, não determinam uma alteração mais intensa na mudança foliar da espécie. É possível que a espécie apresente pulsos curtos de renovação foliar independente da estação, não seguindo um padrão sazonal. Os indivíduos desta espécie, tanto os de áreas de terra firme quanto os áreas sujeitas a inundações, permaneceram sempre verdes, brotando ao mesmo tempo em que perdem as folhas velhas.

De acordo com Jackson (1978), apud Ferraz et al. (1999), a estratégia de reposição de folhas mais vantajosa, numa planta perene, seria a retenção e manutenção da atividade fotossintética das folhas velhas até o crescimento da folhas novas. Essa estratégia resulta em perda contínua de folhas se o brotamento for contínuo, como ocorreu com a andiroba. Jansen (1980) relata que a queda das folhas na estação seca nas florestas tropicais coincide com um primeiro pico de floração, de forma a permitir que a reprodução das árvores se complete, pois as reservas armazenadas, durante a queda das folhas, seriam usadas na frutificação durante o período das chuvas. 


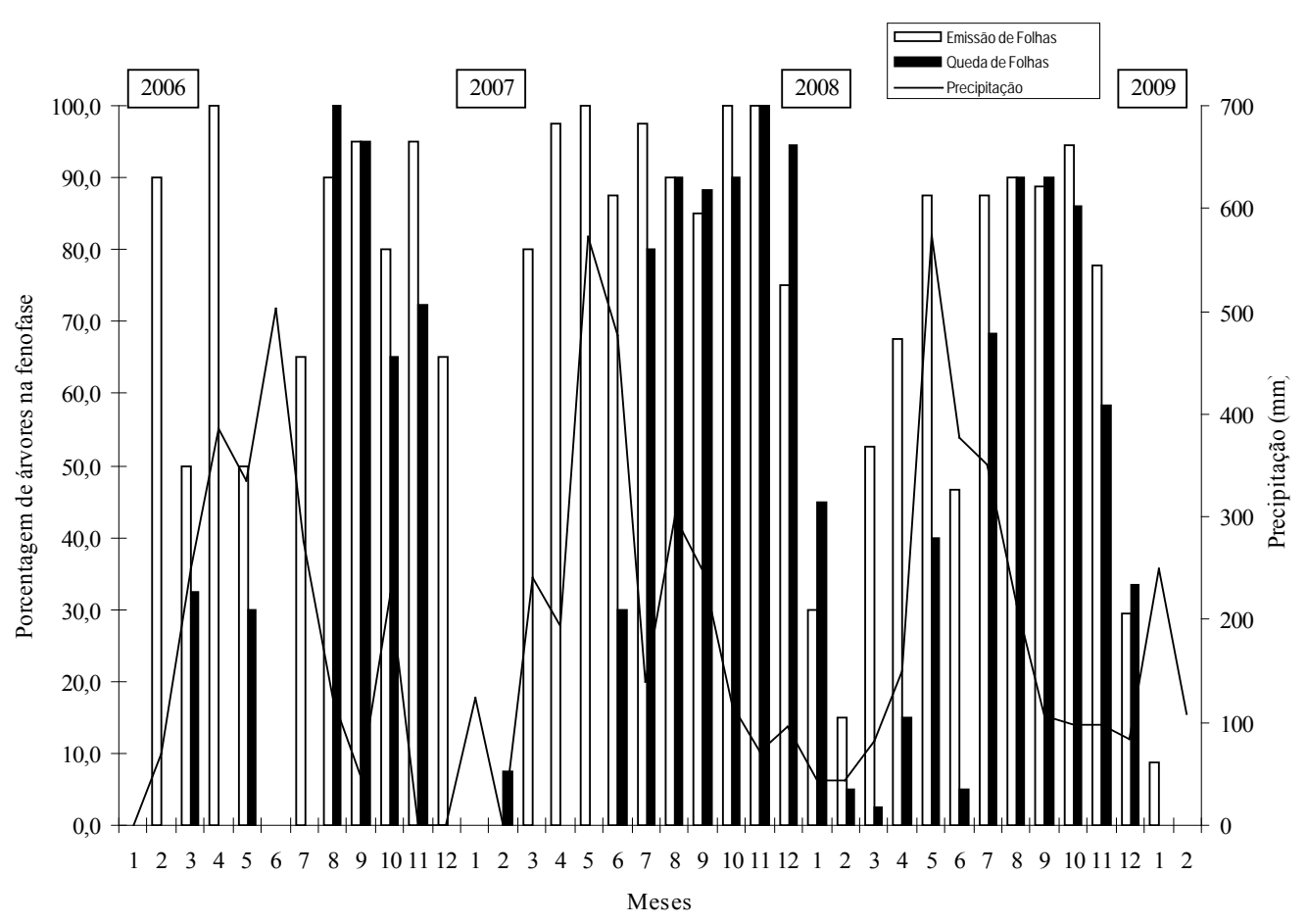

FIGURA 4: Porcentagem de indivíduos de andiroba em emissão e queda de folhas registrada quinzenalmente no período de fevereiro de 2006 a fevereiro de 2009, no município de São João da Baliza, Roraima, Brasil.

FIGURE 4: Percentage of leaf flush and leaf fall for Andiroba trees recorded fortnightly from February 2006 to February 2009 in the city of São João da Baliza, Roraima state, Brazil.

A queda de folhas correlacionouse positivamente e mais fortemente com a precipitação dois meses antes da ocorrência do evento $(r=0,543, p=0,01)$. Para Jordan (1983), o estresse hídrico e a disponibilidade de nutrientes podem influenciar a queda de folhas. A deficiência hídrica temporária é um fator importante mesmo em climas praticamente uniformes com chuvas bem distribuídas. Opler et al. (1976), Auspurger (1983) e Morellato (1991) citam que o principal fator que influencia os padrões fenológicos das espécies tropicais é a precipitação, principalmente em florestas tropicais com estações bem definidas e sazonalidade evidente na precipitação anual.

A emissão foliar não se correlacionou, de forma significativa, com a precipitação, com um grande número de indivíduos emitindo folhas, nas épocas chuvosa e seca. De acordo, Souza (2003), em estudo realizado no Parque Ecológico João Vasconcelos Sobrinho (PEVJS) em Caruaru-PE, cita que a continuidade do brotamento das espécies durante a estação seca provavelmente possui como fatores indutores o aumento do fotoperíodo, a elevação da temperatura e a própria queda das folhas, que parece desencadear o brotamento em algumas espécies. Reich e Borchet (1984) relacionam que a perda de folhas em algumas espécies pode induzir ao brotamento, uma vez que reduziria a perda de água pela planta, produzindo assim a reidratação dos ramos sem folhas e a produção de folhas novas, mesmo em períodos secos. Alencar et al. (1979), em estudo realizado em floresta úmida de terra firme da Amazônia Central, também verificaram que a queda de folhas influencia na emissão de folhas.

\section{CONCLUSÕES}

A floração das andirobeiras mostrouse subanual, com dois ciclos, sincrônica e correlacionando negativamente com a precipitação no período do evento fenológico.

A frutificação é anual, longa, sincrônica e relacionada positivamente com a precipitação. A época ideal para a coleta dos frutos maduros, no local estudado, é durante o período chuvoso, que compreende os meses de abril a julho.

As andirobeiras emitem folhas de forma contínua, independentemente da precipitação. 


\section{AGRADECIMENTOS}

Os autores agradecem à Embrapa e ao Conselho Nacional de Ciência e Tecnologia (CNPq) pelo apoio financeiro. Agradecemos a todos os colegas do projeto Kamukaia: Manejo de Produtos Florestais Não Madeireiros na Amazônia, especialmente a Adebaldo Sampaio Telles e José de Anchieta Moreira da Costa pela dedicação e o esmero na coleta dos dados.

\section{REFERÊNCIAS BIBLIOGRÁFICAS}

AIDE, M. Synchronous leaf production and herbivory in juveniles of Gustavia superba. Oecologia v. 88, n. 4, p. 511-514, Dec.1991.

ALENCAR, J. C. Estudos silviculturais de uma população natural de Copaifera multijuga Hayne Leguminosae, na Amazônia Central. IV. Interpretação de dados fenológicos em relação a elementos climáticos. Acta Amazonica, v. 18, n. 3-4, p. 199-209, jul./dez. 1988.

ALENCAR, J. C. Fenologia de cinco espécies arbóreas tropicais de Sapotaceae correlacionada a variáveis climáticas na Reserva Ducke, Manaus, AM. Acta Amazonica, v. 24, n. 3/4, p.161- 182, jul./dez. 1994.

ALENCAR, J. C. Interpretação fenológica de espécies lenhosas de campina na Reserva Biológica de Campina do Inpa ao norte de Manaus. Acta Amazonica, v. 20 (único), p.145-183, jan./dez. 1990.

ALENCAR, J. C; ALMEIDA, R. A.; FERNANDES, N. P. Fenologia de espécies florestais em floresta tropical úmida de terra-firme na Amazônia Central. Acta Amazonica, v. 9, n. 1, p.163-198, jan./mar. 1979.

AMBITEC. Roraima, O Brasil do Hemisfério Norte. Boa Vista: Fundação do Meio Ambiente e Tecnologia de Roraima, 1994. 512 p.

ANGULO-SANDOVAL, P.; AIDE, M. Leaf phenologyand leaf damage of saplings in the Luquilo Experimental Forest, Puerto Rico. Biotropica, v. 32, p. 415-422, Sept. 2000.

ARAÚJO, V. C. Fenologia de essências florestais amazônicas. 1979. 25 p. (Boletim do INPA No 4).

AUGSPURGER, C. K. Phenology, flowering, synchrony and fruit set of six neotropical shrubs.

Biotropica, Zurich, v. 15, n. 4, p. 257-267, Dec. 1983.

AUGSPURGER, C. K. Reproductive synchrony of a tropical shrub:experimental studies on effects of pollinators and seed predators on Hybanthus prunifolius (Violaceae). Ecology, Washington, v. 62, p. 775-788, Sept. 1981.

BERNOUX, M. et al. Carbon storage in biomass and soils. p.165-184. In: MCCLAIN, M. E.; VICTORIA, R. L.; RICHEY, J. E (eds.). The Biogeochemistry of the Amazon Basin. Oxford: Oxford University Press. 2001.

BORCHERT, R. Phenology and control of flowering in tropical trees. Biotropica, v. 15, p. 81-89, Dec. 1983.

BOUFLEUER, N.T. Aspectos ecológicos da andiroba (Carapa guianensis Aublet. Meliaceae) subsidios para o manejo. 2004. 90 f. Dissertação (Mestrado em Ecologia e Manejo de Recursos Naturais)-Universidade Federal do Acre, Rio Branco, 2004.

BRASIL. Departamento Nacional da Produção Mineral. Projeto RADAMBRASIL. Folha NA.20 Boa Vista e parte das folhas NA 21, Tumucumaque, NB.20 Roraima e NB 21; geologia,geomorfologia, pedologia, vegetação $\mathrm{e}$ uso potencial da terra. Rio de Janeiro, $1975.428 \mathrm{p}$. CALVIN, G. P.; PIÑA-RODRIGUES, F. C. M. Fenologia e produção de sementes de Euterpe edulis MART em trecho de floresta de altitude o município de Miguel Pereira - RJ. Revista da Universidade Rural, Rio de Janeiro, v, 25, n. 1, p. 22-40, jan./ jun. 2005.

CARVALHO, J. O. P. Fenologia de espécies florestais de potencial econômico que ocorrem na floresta nacional do Tapajós. Belém. EMBRAPA/ CPATU. Boletim de Pesquisa da EMBRAPA/ CPATU, n. 20, 15 p. 1980.

EMBRAPA. Espécies Arbóreas da Amazônia. No 02: Andiroba Carapa guianensis. s/p. 2004. Disponível em: http://www.cpatu.embrapa.br/ dendro,tudo1.htm. Acesso em 03 de nov. 2009.

FERRAZ, D. K. et al. Fenologia de árvores em fragmentos de mata em São Paulo. Revista Brasileira de Biologia. v. 49, n. 2, p. 305-317, maio 1999.

FERRAZ, I. D. K.; CAMARGO, J. L. C.; SAMPAIO, P. T. B. Andiroba (Carapa guianensis Aubol.; Carapa procera, D.C) Meliaceae. Manaus:INPA. Manual de sementes da Amazônia, n. 1, 2003, 6 p. FERRAZ, I. D. K.; CAMARGO, J. L. C.; SAMPAIO, P. T. B. Sementes e plântulas de andiroba (Carapa guianensis Aubl. E Carapa procera: aspectos botânicos, ecológicos e tecnológicos. Acta Amazonica, Manaus, v. 32, p. 647-661, abr. 2002. FOSTER, R. B. Ciclo estacional de caida de frutos 
en la isla de Barro Colorado. In: LEIGH, E. G., RAND, A. S., WINDSOR, D. M. (Ed.). Ecologia de um bosque tropical, Balboa: Smithsonian Tropical Research Institute, 1992. p. 219-241.

GASCON, C.; MOUTINHO, P. Síntese. In: Floresta Amazônica: dinâmica, regeneração e manejo. INPA, 1998. 373 p.

GENTRY, A. H. Coevolutionary patterns in Central American Bignoniaceae. Annals of the Missouri Botanical Garden, v. 61, n. 3, p. 728-759. 1974. GONÇALVES, V. A. Levantamento de mercado de produtos florestais não-madeireiros. Santarém: IBAMA- ProManejo, 2001. 65 p.

HALL, P.; WALKER, S.; BAWA, K. S. Effect of forest fragmentation on genetic diversity and mating system in a tropical tree, Pithecellobium elegans . Conservation Biology, Malden, v. 10, n. 3, p. 757768, Jun. 1996.

JANZEN, D. H. Ecologia vegetal nos trópicos. São Paulo: EPU, 1980. 79 p. (Temas de biologia, v. 7).

JANZEN, D. H. Seedling patterns of tropical trees.. In: LINSON, P. B. TOMM; ZIMERMANN (eds). Tropical trees as living systems. Cambridge: University. Press, 1976. p. 88-128.

JORDAN, C. F. Productivity of tropical rain forest ecosystems and the implications for their use as future wood and energy sources. In: GOLLEY, F. B. (ed.) Tropical rain forest ecosystem - structure and function,1983. p. 117-136.

KANASHIRO, M. et al. Improving conservation values of managed forests: the Dendrogene Project in the Brazilian Amazon. Unasylva, v. 53, p. 25- 33. 2002.

LEIGHT E. G. Tropical Forest Ecology. New York: Oxford University Press, 1999. 245 p.

LEITE, A. M. C. Ecologia de Carapa guianensis Aublet. (Meliaceae) "andiroba".1997. 181 f. Tese (Doutorado em Biologia Ambiental)-Universidade Federal do Pará/Museu Paraense Emilio Goeldi, Belém, 1997.

LENTINI, M. et al. Fatos Florestais da Amazônia 2005. Belém: Imazon. $2005.141 \mathrm{p}$.

LIMA JÚNIOR, M. J. V. Fenologia de cinco espécies de Lecythidaceae da Reserva Florestal Ducke, Manaus-AM. 1992.72 f. Dissertação (Mestrado)-Instituto Nacional de Pesquisas da Amazônia/Fundação Universidade do Amazonas, Manaus, 1992.

LOUREIRO, A. A.,; SILVA, M. F.; ALENCAR, J. C. Essências madeireiras da Amazônia, V.2. Manaus: INPA/SUFRAMA, 1979, 187 p.

MAUÉS, M. M. Estratégias reprodutivas de espécies arbóreas e a sua importância para o manejo e conservação florestal: Floresta Nacional do Tapajós (Belterra-PA). 2006. 206 f. Tese (Doutorado em Ecologia)-Universidade de Brasília, Brasília, 2006.

MELLINGER, L. L. Aspectos da regeneração natural e produção de sementes de Carapa guianensis Aubl. (andiroba) na Reserva de Desenvolvimento Sustentável Amanã (AM). 2006. 81 f. Dissertação (Mestrado em Ciências Biológicas)-Instituto Nacional de Pesquisas Amazônicas/Universidade Federal do Amazonas, Manaus, 2006.

MORELlATO, L. P. C. Estudo da fenologia de árvores, arbustos e lianas de uma floresta semidecídua no sudeste do Brasil.1991.176 f. Tese (Doutorado em Ecologia)- Universidade Estadual de Campinas, Campinas, 1991.

MORELLATO, L. P. C. et al. Estudo comparativo da fenologia de espécie arbórea de floresta de altitude e floresta mesófila semi-decídua na Serra do Japi, Jundiaí, São Paulo. Revista Brasileira de Botânica, v. 12, p. 85-89, dez. 1989.

NEWSTRON, L. E; FRANKIE, G. W. A new classification for plant phenology based on flowering patterns in lowland tropical rain forest trees at la selva, Costa Rica. Biotropica, Zurich, v. 26, n. 2, p. 141-159, Jun. 1994.

OPLER, P. A.; FRANKIE, G. W.; BAKER, H. G. Comparative phonological studies of treelet and shrub species in tropical wet and dry forest in the bowlands of Costa Rica. Journal of Ecology, v. 68, p. 189-209, 1976.

PENA, J. W. P. Frutificação, produção e predação de sementes de Carapa guianensis AUBL. (Meliaceae) na Amazônia Oriental Brasileira. 2007. 60 f. Dissertação (Mestrado em Ciências Florestais)-Universidade Federal Rural da Amazônia, Belém, 2007.

PENNINGTON, T. D.; STYLES, B. T.; TAYLOR, D. A. H. Meliaceae. Flora Neotropica Monograph, n.28, 1981. $470 \mathrm{p}$.

PETERS, P. J.; READ, J.; SANSON, G. D. Variation in the guild composition of herbivorous insect assemblages among co-occuring plant species. Austral Ecology, v. 26, p. 385-399, Aug. 2001.

PINTO, A. M. et al. Fenologia de Simarouba amara Aubl. na reserva florestal Adolpho Ducke, Manaus, AM. Acta Amazonica, v. 35, n. 3 , p. 347-352, jul./ set. 2005.

PLOWDEN, C. The Ecology and harvest of andiroba seeds for oil production in the Brazilian 
Amazon. Conservation e Society, v. 2, n. 2, p. 251270, Mar. 2004.

QUEIROZ, J. A. L. Guia Prático de Manejo Florestal para a Produção de Frutos de andiroba (Carapa guianensis Aubl.) e de outros produtos de valor econômico no estado do Amapá. IEPA. 2007. $38 \mathrm{p}$.

RAPOSO, A.; SILVA, J. M. M.; SOUSA, J. A. Estudos fenológicos de andiroba (Carapa guianensis) no município de Rio Branco-AC. In: CONGRESSO NACIONAL DE BOTÂNICA, 54., 2003, Belém. Anais...Belém: UFPA, 2003. Disponível em: http://www.adaltech.com.br/ evento/museugoeldi/resumoshtm/resumos/R04371.htm . Acesso em 20 de jul. 2008.

RATHCKE, B.; LACEY, E. P. Phenological patterns of terrestrial plants. Annual Review of Ecology and Systematics, Palo Alto, v. 16, p.179-214, Nov. 1985.

REICH, P. B., BORCHET, R. Water stress an tree phenology in a tropical dry forest in the lowlands of Costa Rica. Journal of Ecology, v. 72, p. 61-74, 1984.

REVILLA, J. Plantas da Amazônia: oportunidades econômicas e sustentáveis. Manaus: Programa de Desenvolvimento Empresarial e Tecnológico, 2000. $405 \mathrm{p}$.

RIZZINI, C. T.; MORS, W. B. Botânica Econômica Brasileira. São Paulo: EPUSP, 1976. 207 p.

SAMPAIO, P. de T. B. Andiroba (Carapa guianensis). In: CLAY, J. W.; SAMPAIO, P. de T. B.; CLEMENT, C. R. Biodiversidade Amazônica: exemplos e estratégias de utilização. Manaus: Programa de Desenvolvimento Empresarial e
Tecnológico. 2000. p. 243-251.

SCARANO, F. R.; PEREIRA, T. S.; RÔÇAS, G. Seed germination during floatation and seedling growth of Carapa guianensis a tree from floodprone forests of the Amazon. Plant Ecology, v. 168, p. 291-296, 2003.

SHANLEY, P. Andiroba (Carapa guianensis, Aublet.). In: SHANLEY, P.; MEDINA, G. Frutíferas e plantas úteis na vida amazônica. Belém: Cifor, 2005. p. 41-50.

SILVERTOWN, J. W. The evolutionary ecology of mast seeding in trees. Biological Journal of Linnean Society, v. 14, p. 235-250, 1980.

SOUZA, E. M. Fenologia e relação abelhas/ plantas em uma comunidade de Mata Serra (Brejo de Altitude) no nordeste do Brasil. 2003. 173 f. Tese (Doutorado em Biologia Vegetal) Universidade Federal de Pernambuco, Recife, 2003. TONINI, H.; COSTA, P.; KAMINSKI, P. E. Estrutura, distribuição espacial e produção de sementes de andiroba (Carapa guianensis Aubl.) no sul do estado de Roraima. Ciência Florestal, Santa Maria, v. 19, n. 2, p. 1-6, abr./jun. 2009.

TUTIN, C. E. G.; FERNANDEZ, M. Relationships between minimun temperature and fruit production in some tropical forest trees in Gabon. Journal of Tropical Ecology, Aberdeen, v. 9, p. 24128, Aug. 1993.

VAN SCHAIK, C. P.; TERBORGH, J. W.; WRIGHT, J. The phenology of tropical forests: adaptive significance and consequences for primary consumers. Annual Review of Ecology and Systematics, Palo Alto, v. 24, p. 353-377, Nov. 1993. 